\title{
Impact of Halal Digital Marketing on Consumer Behavior: Jordan's Perspective
}

Submitted 20/03/20, 1st revision 15/04/20, 2nd revision 20/05/20, accepted 15/08/20

\section{Khalid Mohummed Alomari ${ }^{1}$, Aya Naser Yousef Maqableh ${ }^{2}$, Ali A. Salah ${ }^{3}$, Khaled (M.K) Ismail Alshaketheep ${ }^{4}$ Ahmad Abdullah abu Jray ${ }^{5}$}

\begin{abstract}
:
Purpose: The main aim of this article is to study the Halal digital marketing and how it is different from the conventional marketing in an Islamic country like Jordan.

Design/Methodology/Approach: This study reviews recent research on the role digital marketing plays in consumer behaviour. This paper aims to shed light on the position halal digital marketing in Jordan's consumer behaviour. Data was gathered by questionnaires from 216 residents of Jordan. The comparisons analysis was performed and then a multiple regression was used to test the hypotheses following confirmation of normality, validity and reliability of a process sample.

Findings: The results indicate that there is a significant relationship between Halal Marketing and Consumer Preference. The customers tend to get attracted towards the products which are advertised by following the Shariah guidelines. Since Jordan is an Islamic nation, that is why people over there prefer Halal Marketing over Conventional.

Practical Implications: All the organizations which can market their products by adhering to Shari'ah guidelines can implement halal ways of marketing rather than conventional as customers prefer the former as compared to latter.

Originality Value: This is the first paper which has analyzed the consumer's preference towards Halal Marketing in Jordan.
\end{abstract}

Keywords: Consumer Behaviour, Halal Digital Marketing, Jordan.

JEL codes: M31, M32.

Paper Type: Research study.

\footnotetext{
${ }^{1}$ Assistant Professor, Business Department, College of Business and Economi Al-Hussein Bin Talal University, khaled@ahu.edu.jo

2(Ph.D) Research scholar, Faculty of business, Economics and Social Development,

University Malaysia Terengganu (UMT) ayanmagableh@gmail.com

3Associate Professor, Business Department, College of Business and Economics. Al-Hussein

Bin Talal University, aliataslah@yahoo.com

4Research scholar, k.alshikh@gmail.com

5(MBA) Research scholar, a.aljery@ahu.edu.jo
} 


\section{Introduction}

The sale of goods and services in Muslim countries poses a very difficult challenge for MNCs, given the variations in political, economic, and socio-cultural aspects. Meanwhile, because MNC makes up around twenty percent of the population of the world, it was not able to "evirate" toward Muslim countries as its source of growth. It is also expected that this figure will increase to $30 \%$ by 2025 . One of the main principles of Islam is the concept of halal, which is "allowable." Slaughter, storage, display, preparedness, and sanitation aspects are covered at Halal. It covers all categories of non - food and products. Despite the rapid pace of trade globalization, progress in science and technology and efforts to simplify production processes make it important for marketers to have a full understanding of Halal.

\subsection{Marketing in Jordan}

Jordan is a tiny, fairly "modern" nation that acquired independence just 100 years ago. Due to the influx of refugees from neighboring Palestine and Syria, given Jordan's novelty, its overall population is relatively high for a small nation - some 8 million in 2015. Ninety-seven percent of the population is Muslim, with the remaining three percent largely Muslim. Jordan's youth is still disproportionately young, with around 42.2 percent under-15 youth. The economy of the nation is one of the weakest in the Middle East and depends heavily on foreign assistance and tourism. Jordan's natural resources are scarce. It is currently serving on the UN Security Council and will have a GDP of \$37.52 billion in 2015-2020 Marketers seeking an audience in Jordan have aimed their digital campaigns at an official unemployment rate of 13 percent and 30 percent at unofficial pace, taking into account the young people, Muslim populations, as well as emerging economies.

Present legislation and detailed terrorist and intelligence definitions, marketing companies aiming for a market in Jordan would be designing their interactive initiatives, taking into account young people and the nation's biggest Muslim group, and the growing economy, with a 13 percent unemployment rate informal media and an unofficial 30 percent. With new laws and more specific definitions of terrorism and insufficient content. By the Jordan Press and Publication Act, the prohibited content covers "all material incompatible with the principles of liberty, national duties, human rights, and Arab-Islamic values." Jordanian advertisers should take into account the wide and stringent content restrictions in Jordan and focus on national and cultural advertisements, especially on the subjects of faith, political rights, and the Jordanian Government and the Royal Family.

\subsection{State of E-Commerce in Jordan}

In 2015, the Jordan Times published a MasterCard report reporting that only 5 percent of Jordan's transactions accounted for online transfers with 95 percent of Kingdom acquisitions in money. Despite the increasing adoption of smartphones in the country, 
which reported around 55\% in the same post in 2015-2020. Such e-pay purchases are for demand services like games and telephones and not conventional e-commerce. The explanation of Jordan's small online and smartphone e-commerce rates is cited as confusion around potential fraud and relative security of traders' immediate cash receipts. The MasterCard Market Manager confirmed that the majority of Jordanians are technologically sound and are ready to use credit cards and e-payments as a result of their young age. In Jordan this year, e-commerce is increasing because of the rise in the Internet, and the mobile and demand penetration of young Jordanians. The only problem which prevents the growth of e-commerce is Jordan's insecurity. In order to address this problem, MasterCard has initiated partnerships with traders and expects to significantly increase the use of eCommerce in the country.

The latest trend is also stimulating e-commerce in Jordan: CashU is an electronic payment system which uses pay cards and not credit cards. Google reports that Jordan accounts for about $95 \%$ of the market in Jordan, with CashU being increasingly common in retail and banking, according to Statsmonkey's 2014 analysis. Many wellknown websites like Yahoo and Bing have a market share of less than 2\%. Google's huge monopoly in Jordan's search engine markets shows that marketers will do all they can to get the most impressions of Google.

Jordan SEO Situation: A study of relative optimization schemes for search engines is provided in the United Says and Jordan. In contrast, we do the top-page search metrics in Arabic for common searches of the US and Jordan for "hotels" and "cars." The volume of capital-passing relationships and the amount of confidence on the landing pages should inform the SEO between the United States and Jordan about its relative competitiveness.

PPC state Jordan: Fewer companies paying ads and lower requirements for SEO on Google Jordan to score high, Jordan PPC marketers have lower offers and less competition for top-ranking advertising than in Jordan. Jordan PPC state PPC says with Jordanian publicity, start-up and low budget companies can increase their expectations and revenues. The Jordan Times published few surveys in 2014 showing nearly $95 \%$ of Jordanians have mobile, with about $38 \%$ of the population using smartphones.

Jordan's social network: The nation is the second in the Arab world to have a deep penetration rate in the internet on smartphones. Owing to its fast internet and Smartphone penetrating, Jordanians are very involved on sites with social networking networks, with 28 percent utilizing their telephones to reach such sites, 84 percent of Jordanians are using social Web sites, like Facebook and Twitter.

According to that number and figures in the Dubai School of Governance and Technology 2015 Arab Social Network Survey, Jordanians participate heavily in various social network types. Jordan has the highest preferences for Facebook in the Middle East and also showed its strong allegiance to Twitter, 63\% of the country's 
web is signed up and posted every day. This participation in a broad range of social networking platforms provides marketers with an excellent opportunity to view advertising via a variety of networks.

\subsection{Jordan Internet Marketing Condition}

Jordan's mobile market seems to lag in a nation with such strong smartphone and internet penetration. This is mainly due to general distrust in providing online card retailers and Jordanians with details. Most Jordanian transactions are strong, fast, secure currency. According to a GMSA Intelligence report, "The Internet Economy Arab States 2015," Jordan's penetration of mobile money (in the form of banking applications and e-payment systems such as PayPal) in Jordan is less than 30\%, which is very low compared to other Arab countries such as the US and Bahrain with $70 \%$ penetrating rates. Jordan's strong growth in internet penetration, smartphone use and presence on social media websites have rendered the lack of growth in these facilities even more alarming in recent years.

The lack of digital literacy is another factor in Jordan's mobile marketing-roughly two-nine percent of Jordan's calls reported seeking assistance in the use and understanding of mobile service. However, the biggest obstacle to a flourishing mobile market is the high mobile charge. Jordanian telecom taxes are continually changing and growing, rendering it volatile and cost-effective. This impacts not only telecommunications firms, but Jordan as a whole increases the cost of purchasing and storing mobile information, and the economy is deteriorating due to lack of connectivity and large Syrian refugee inflows. While Jordan's mobile market is not currently competitive enough, the current tax situation and economy could prevent the market from thriving in the future, and mobile advertising investments will not be restored.

There is plenty of room for lucrative display ads in Jordan, where digital media investment is one of the highest in MENA, with an ad budget of about \$140 million in 2015-2020. Besides 66 percent of YouTube's countrywide use, there are also many opportunities for popular display ads on a number of social media websites.

\section{Literature Review}

Consumer behavior analysis, including both payor and customer, is a buying behavior test. Therefore, business awareness is essential to investigate consumer buying behavior. Predicting customer purchasing is very challenging as products and services are the main buyers (Gajjar, 2013). Most factors can affect consumer behavior, such as cultural and social factors. The perception was a process in which a person selects, organizes, and interprets something to understand better (Mutsikiwa and Basera, 2012). Perception plays a major role in determining consumer behavior as it affects the buyer's buying decisions (Rezai, 2008). 
Al-Maroof and Al-Emran (2018), Al-Qaysi and Al-Emran (2017), Al-Qaysi, Mohamad-Nordin, and Al-Emran (2018), Alshurideh, Salloum, Al Kurdi, and AlEmran (2019) due to the rapid dissemination of technologies and knowledge on the Internet across various channels such as tablets, social networking platforms and word - of - mouth online. Such advances make the planet look like a small village, promoting access and consumer engagement (Alghizzawi, Salloum, and Habes, 2018; Malik and Al-Emran, 2018; Salloum, Al-Emran, Shaalan, and Tarhini, 2019).

Consumers want wireless communication networks for product knowledge and services. It was people's everyday existence (Stephen, 2016). Worldwide, the number of internet users exceeded 4.1 trillion, with 92 percent smartphone accessing the web. 3.56 billion registered active social network users (date info, 2018). Many consumers utilize digital marketing and social media as customers of goods and services intensively as they search for knowledge and data on purchased items and post their experiences with others (Salloum and Shaalan, 2018) which reacts more often to marketers of this fundamental transformation by using digital marketing channels. Indeed, by 2020, nearly two-thirds of customer spending is expected to be spent on internet channel-streamed ads (Park and Lee, 2008). However, customer marketing is increasingly being applied in digital environments, especially in social media and cell phones.

Ideology is a set of beliefs and practices that perceive and react to people's spiritual, religious feelings (Johnstone, 1975). Many denominations endorse, or forbid, such as consumer behaviors. Schiffman and Kanuk (1997) argue that members of different religious groups can make purchase decisions affected by their religious identity. This is commonly known in multinational business and communications manuals. Religion has attracted interest from scholars and marketers and is a marketing under-research subject (Cleveland, Laroche, and Hallab, 2013). Religiosity is separate from Christianity. Religion refers to particular religion or belief, such as Islam, which is a Muslim belief or belief in Islam, Sunni faith, and Shia faith are also subdivided. But religiosity is described as "the extent to which a person retains religious principles, morals, and beliefs in particular" (Safiek and Mokhlis, 2008). Mokhlis (2009) said religion is considered a demographic variable like gender and age. Therefore, religious belief and religiosity are different.

The political association is commonly referred to as the specific religious or denominational participation of people in each region, although faith or social affiliations differ from moral affiliations and can be established at cognitive and behavioral levels. The cognitive norm refers to the extent of an individual's religious views (Mokhlis, 2009).

Religiosity can be defined as "the degree of religiosity," but a multifaceted concept encompasses many facets of example beliefs, experiences, and activities that affect the whole existence of each person (De Run et al., 2010). Johnson (2001) claimed that religiosity is the extent to which an individual's devotion to faith represents that 
dedication, such as individual attitudes and behavior. The extent to which a person uses religious values, beliefs, and traditions in daily life is described as religiosity. The belief is that a strong religious individual can see the future through divine schemes, integrating his Christianity into much of his existence.

Faith and consumer behavior research indicate that two religious views influence consumer behavior. First, faith work at the macro - level and allows its adherents to follow those values. Such ideals have been recognized as fundamental beliefs at national level, and parents motivate and inspire children to adopt the same values so that they conform to society because of common interest. Second, according to the principles and rules of a religion, religious devotion and religiosity affect the attitudes and actions of consumers within a religion (Arnould, Price, and Zinkhan, 2004; Schiffman and Kanuk, 2010).

According to Patel (2012), religiousness is an extremely important cultural and religious factor and can influence consumer behavior as consumer behavior is often categorized in the religion of target audience. The extent to which religion affects consumer behavior depends on religiosity. Religiousness influences consumer behavior by influencing a person's personality structure that, according to Mokhlis (2010), includes his/her beliefs, values and habits.

Christian religious followers with a strong religious standard embrace divine belief positively and explicitly and follow all principles, rules, standards and virtues of their religion. They pray actively, have alms and charity, and hold daily community gatherings. But, on the other hand, Christians with weak religiosity are seen as liberal and democratic, who feel free to fulfill religious obligations. Therefore, the degree of individual religiosity should be weighed when assessing the nature of customer behavior (Safiek and Mokhlis, 2010).

There is a notable case for religious behavior and lifestyles on Muslim markets, but religious belonging rates vary worldwide, which is why religious belonging influences the background of consumer behavior (Safiek and Mokhlis, 2010). It is also clear that moral duty rules are harsher for highly religious Muslims (Taks and Shreim, 2009).

Under De Run et al. (2010), literature analysis indicated that the degree of religious participation in gender-related goods was a major factor. They found that genderbased goods are more troublesome than those with no religiosity for highly spiritually engaged people. According to Run et al. (2010), the rapid growth of satellite channels in Muslim countries and the growing number of controversial advertising and advertising of controversial products could have made people more tolerant of them and increased the acceptability of controversial products in Muslim societies, especially in younger generations. Given chances of group differences within a Muslim society about controversial products and their age-based publications, gender, education, and income. 
Religiosity has a discernible effect on Muslim consumers' attitudes and behaviors (Shin, Park, Moon and Kim, 2010; Ansari, 2014). It is also clear that highly religious Muslims follow religious duty laws more rigorously than lower-religious Muslims (Taks and Shreim, 2009). When Muslim clients become more acquainted with their religion, they gradually become more particular about the type of goods they purchase or use. Moreover, as consumers are becoming increasingly sophisticated in matters of diet and health, the importance of informative labeling and the right to be properly informed will be strengthened.

In the last decade, there has been a significant increase in interest in researching advertisements and religion's effects and relationships. Before this, the Gulf Cooperative Council countries had only a few reports on Islamic advertising issues (Rice and Al-Mossawi, 2002). While more scholars are researching this area, current studies examine Islam in theological and jurisprudential terms through a holistic view without understanding the presence of differences of opinion on Islamic law (Shari'ah) interpretation. Hence, most studies tend to generalize. However, Saudi Arabia 's theological definition is considered more conservative than other Muslim nations (Rice and Al-Mossawi, 2002).

\subsection{Islamic Advertising}

Throughout the late 1980s, Islamic commercial solidarity started to grow. Scholars from Islamic countries including Saudi Arabia and Malaysia focused on advertising. In the past decade, more work on Islamic marketing has been undertaken with specialist publications to tackle numerous Islamic and marketing concerns (Wilson, 2012). Previous Quranic and Prophetic-based empirical review studies (Luqmani et al., 1989). Several scholars have indicated material analysis of current ads and other advertisements campaigns for U.S. or British approaches throughout Islamic countries (Kalliny, 2010; Al-Makaty et al., 1996). Their research explained that Islam advertises controlled ads. Rice and Al-Mossawi (2002) categorized target groups as Muslims without acknowledging their moral beliefs or spiritual activity.

Similarly, Muslim public placed more focus on Islamic matters. Wilson (2012) claimed that advertisers in Middle Eastern countries will be conscious of Islamic concepts, beliefs and religious practices. Luqmani in 1989, noted a significant percentage of the theologically adhering community would be oppressed by denying faith's impact on advertising, especially Islam. Family and some (2004) suggested that the amount was detrimental in the displaced community. The dissatisfied group may also influence society's outlook and negatively affect customer perceptions (Michell and Al-Mossawi, 1999). Luqmani (1989) noted that religious authorities play an important role in mark perceptions in the conservative segment of population. But Islam's effect on promotional strategies is not seen in recent studies as the influence of Salafism in Saudi Arabia, or as hannbalism jurisprudence. 
According to Luqmani et al. (1989) it helps to build a foundation on which Islam affects Saudi Arabia's advertising. Identified three Quranic teachings concerning advertising: 1. Taboos (Haram): food, loteries, false advertising, idol pictures and women's non -Islamic images; 2. Reverence for Islamic duties like Islamic prayer; 3. Thanks to Allah for His blessings. Rice and Al-Mossawi (2002) studied focused on classrooms in Islamic advertising. They noted that women's role in advertising across the Muslim world is different due to religious interpretations. Islam and publicity studies are currently prioritized to demonstrate positive actions, in contrast to challenges such as sins representation (Luqmani et al., 1989; Rice and Al-Mossawi, 2002; Kalliny 2010, Fam et al., 2004).

Gender stereotypes depend on Islamic advertising (Rice, 2004; Rice and Al-Mossawi, 2002), and inmorality shows (Alserhan and Alserhan 2012; AlAbdali 2009; Tuncalp 1992; 1989; Nassif, 2008; Kalliny, 2010; Olayan, 2013).

An earlier evaluation of technology acceptance in Jordan shows the nation is strong enough in terms of technical and professional readiness. However, it needs social impetus to balance the actual development with the technological resources. Consumers and companies in Arab countries, including Jordan, use very little digital marketing. It also stated that Jordanian small and medium-sized businesses remain on a low level of digital marketing due to a variety of factors such as lack of top management support, lack of personnel with low understanding of protection and privacy, lack of confidence, regulatory standards and sluggish site operation, and lack of decision-makers in Jordanian small and medium-sized enterprises including Jordan's websites, Arab websites pose a big design issue, most of which are misleading and valuable information normally not seen. This would certainly have a negative impact on consumers in retaining market ties. The presence is critical for supporting its identity and generating essential knowledge.

\section{Methodology}

A questionnaire was used for data collection. The Likert scale of five points, which ranges from strongly agreed to disagree, measured two major proportions, including consumer behavior and halal digital marketing. Each variable had certain set of questions, Halal Digital marketing comprised of questions related to transparency, portrayal of women, specific Ramadan and Eid offers and ads, promotion of alcohol or tobacco related products and customer behaviour included questions related to how customers get attracted after seeing ads which are adhering Islamic rules and laws, does it impact their purchasing behavior or not. The objective of the paper is to whether there is a significant difference between halal digital marketing and consumer behaviour. SPSS version 23 was used for the data processing, and all experiments were performed in a 5 percent standard. Descriptive figures identified the key demographic characteristics of the survey. The theoretical gender stereotypes were tested for equal treatment with an independent $\mathrm{T}$ - test survey. ANOVA was used to compare the means. Linear regression has also investigated the effect of the 
hypothesized frameworks. There are actually 216 people in the sample living in Jordan.

\section{Discussion}

\subsection{Results of Demographics}

In describing the population variables of the study (Table 1), a descriptive approach was used. Of the 216 respondents in population, 132 were men and 84 were women. The age of most respondents $(50 \%)$ is in the $20-30$ years age group while $44,4 \%$ is in the $30-40$ years age group. $5.6 \%$ of respondents fall into the 40 year category.

Table 1. Descriptive Statistics of Demographics

\begin{tabular}{|l|l|l|l|l|}
\hline & Gender & Mean & Std. Deviation & Percent \\
\hline \multirow{3}{*}{ Gender } & Male & 2.1125 & .62062 & 61.1 \\
\cline { 2 - 5 } & Female & 2.0833 & .64627 & 38.9 \\
\hline \multirow{4}{*}{ Age } & $20-30$ & 1.50 & .577 & 50.0 \\
\cline { 2 - 5 } & $30-40$ & 2.25 & .886 & 44.4 \\
\cline { 2 - 5 } & $>40$ & 2.67 & .577 & 5.6 \\
\hline \multirow{5}{*}{ Occupation } & Student & 2.25 & .957 & 56.5 \\
\cline { 2 - 5 } & Govt. Employee & 3.00 & .000 & 26.9 \\
\cline { 2 - 5 } & Employee & 2.71 & .488 & 11.1 \\
\cline { 2 - 5 } & Others & 2.45 & .880 & 5.6 \\
\hline
\end{tabular}

Source: Own calculations.

Table 2 represents descriptive for strategic leadership and innovation performance. The descriptive of both the variables were fairly in the range, Halal Digital Marketing (3.11) and Consumer Behavior (3.58)

Table 2. Descriptive Statistics of Variables

\begin{tabular}{|l|l|l|l|l|l|}
\hline & $\mathrm{N}$ & Minimum & Maximum & Mean & Std. Deviation \\
\hline HalalDigiM & 216 & 2.33 & 4.17 & 3.11 & .53103 \\
ConsumerP & 216 & 3.00 & 4.60 & 3.58 & .34054 \\
Valid N (listwise) & 216 & & & & \\
\hline
\end{tabular}

Source: Own calculations.

\subsection{Independent Sample t-Test}

An additional analysis has been carried out using an independent sample test for comparing the meaning between male and female levels in the major study variables (Table 3). The sample variance was therefore assumed to be equal ( $p>0.05)$ in halal digital marketing and consumer behavior. The average for men was higher in terms of their perception on halal marketing than female respondents, while the average for females was higher for consumer behavior and perception. Since the sig value is more 
than .05, male and female disparity in Halal Digital Marketing and Customer Enforcement is important.

Table 3. Independent Sample t-Test

\begin{tabular}{|l|l|l|l|l|l|}
\hline & Mean & SD & $\begin{array}{l}\text { SD Error } \\
\text { Difference }\end{array}$ & $\mathrm{t}$ & Sig. \\
\hline Male & 3.17 & .500 & .043 & 2.00 & 0.14 \\
\hline Female & 3.01 & .565 & & & \\
\hline Halal Digital Marketing & \multicolumn{5}{|l|}{} \\
\hline Male & 2.4792 & .50139 & .25998 & 1.853 & 0.173 \\
\hline Female & 2.6667 & .65168 & & & \\
\hline \multicolumn{7}{|l|}{ Consumer Behaviour } &
\end{tabular}

Source: Own calculations.

\subsection{ANOVA Results}

Table 4 shows the results from the post-hoc Tukey HSD one-way ANOVA test to compare mean distinctions of theoretical constructs from ordinary demographic categorical variables (gender, age and teaching experience). Statistically significant differences occur from the results among the groups as a whole (all p>0.05). Multiple comparisons in age indicate that the groups differed. The Tukey after-hoc test reveals a higher knowledge of halal digital commercialisation by medium-aged customers (30-40 years), but the customers of this range are eager to purchase products with halal digital ads over 20-30 years (midrange=3.27 and 3.60). The students are more conscious of and likely to purchase such items in relation to their knowledge of halal digital marketing, with a mean of 3,24, 3,59 and above workers, the unemployed and others. The difference in significance between the whole variable in digital halal marketing and consumer behaviors was more than 5 per cent.

Table 4. ANOVA with post-hoc Tukey HSD

\begin{tabular}{|c|c|c|c|c|}
\hline Variable & \multicolumn{2}{|c|}{ Halal Digital Marketing } & \multicolumn{2}{|c|}{ Consumer Behaviour } \\
\hline & Mean & Significance & Mean & Significance \\
\hline Male & 3.17 & \multirow{2}{*}{0.037} & 3.59 & \multirow{2}{*}{0.667} \\
\hline Female & 3.01 & & 3.57 & \\
\hline \multicolumn{5}{|l|}{ Age } \\
\hline $20-30$ & 2.99 & \multirow{3}{*}{0.43} & 3.60 & \multirow{3}{*}{0.814} \\
\hline $30-40$ & 3.27 & & 3.57 & \\
\hline$>40$ & 2.94 & & 3.56 & \\
\hline \multicolumn{5}{|l|}{ Occupation } \\
\hline Student & 3.24 & \multirow{2}{*}{0.07} & 3.59 & \multirow{2}{*}{0.123} \\
\hline Employee & 3.01 & & 3.44 & \\
\hline Unemployed & 2.75 & & 3.400 & \\
\hline Other & 3.00 & & 4.60 & \\
\hline
\end{tabular}

Source: Own calculations. 


\subsection{Regression Results}

The results show that there are statistically significant positive linear relations/ effects between the variables from the three hypothesized framework settings. For evaluation of these models, the entry method was used. In order to test homoscedasticity and normality of residual substances, Durbin-Watson self-relation test was used. Table 5 presents the results of the simple linear regression models. A single linear regression model was examined to determine if there is a statistically important positive linear relation/effect of halal digital marketing on consumer behaviour. Consumer behavior was modelled and this resulted in a substantial model as an explicatory/independent variable). Table 5 presents the model and summary statistics. Durbin-Watson $d=2.37$ is between the two $1.5<\mathrm{d}<2.5$ crucial values and we can thus assume that in our linear regression data there is no first order linear auto-correlation.

Table 5. Regression Analysis

\begin{tabular}{|c|c|c|c|c|c|c|}
\hline & & Sum of Squares & Df & Mean Square & $\mathrm{F}$ & Sig. \\
\hline 1 & Regression & 2.702 & 1 & 2.702 & 9.981 & .07 \\
\hline & Residual & 57.926 & 214 & .271 & & \\
\hline & Total & 60.628 & 215 & & & \\
\hline & rvation & & & & & \\
\hline & t. standard er & & & & 45 & \\
\hline & & & & & 11 & \\
\hline & ange (Sig. F & hange) & & & 81 & \\
\hline & in Watson & & & & & \\
\hline
\end{tabular}

Source: Own calculations.

\section{Conclusion}

Religious attitudes played a major role in shaping customers' behavior in the $21 \mathrm{st}$ century (Patel, 2012). Religiosity forms the behavior of people significantly (Tarkang, 2013). The religious principles of the community also played a major role in the formation and influences of human beliefs, attitudes and actions (Qamar, Lodhi, Qamar, Habiba and Amin, 2014). The empirical results show that religiousness is included in future studies and that extensive studies can be carried out about the influence of faith on customer behavior (Essoo and Dibb, 2010).

Researchers suggested that the ethical choices made by people over products, services and ideas could be influenced by faith (Weaver and Agle, 2002). In the last 30 decades considerable efforts have been made to create the connection between mainstream and subcultural customer conduct principles and aspects. However, consumer researchers have incorrectly analyzed the focus on faith as an intrinsic human value (Mokhlis, 2010; Mokhlis, 2009; Khraim, 2010; Haque, Rahman, and Haque, 2011). Ansari (2014) has stated that religion is neglected in customer evaluations and, consequently, less attention is paid to religion to understand consumer behaviour, because most 
academics are less religious than the public. Although studies in consumer literature are limited, most students ignore this area.

In order to achieve an accurate knowledge of customer desires and behaviours, religion and market analysis will be carried out with the same rigor and objectivity as other influential social factors (Ansari, 2014). Future work is undertaken to assess how social influences affect customer behavior (political values, culture and religion). Studies must also be carried out in conservative religious societies because people in religious societies are more affected by their religion, which eventually affects their purchasing and consuming behavior. In the potential empirical work, studies of controversial subjects relevant to religion should also focus on this ignored field.

\section{References:}

Alabdali, O.S. 2009. Saudi consumers' attitudes towards advertising: a contemporary perspective. Journal of International Business and Entrepreneurship Development, 4(4), 265-274.

Alghizzawi, M., Ghani, M.A., Som, A.P.M., Ahmad, M.F., Amin, A., Bakar, N.A., Habes, M. 2018. The impact of smartphone adoption on marketing therapeutic tourist sites in Jordan. International Journal of Engineering \& Technology, 7(3-4), 91-96.

Al-Maroof, R.A.S., Al-Emran, M. 2018. Students acceptance of Google classroom: An exploratory study using PLS-SEM approach. International Journal of Emerging Technologies in Learning (IJET), 13(6), 112-123. https://doi.org/10.3991/ijet.v13i06.8275.

Al-Qaysi, N., Al-Emran, M. 2017. Code-switching Usage in Social Media: A Case Study from Oman. International Journal of Information Technology and Language Studies, 1(1), 25-38.

Al-Qaysi, N., Mohamad-Nordin, N., Al-Emran, M. 2018. A Systematic Review of Social Media Acceptance from the Perspective of Educational and Information Systems Theories and Models. Journal of Educational Computing Research. https://doi.org/https://doi.org/10.1177/0735633118817879.

Alshurideh, M., Salloum, S.A., Al Kurdi, B., Al-Emran, M. 2019. Factors affecting the Social Networks Acceptance: An Empirical Study using PLS-SEM Approach. In 8th International Conference on Software and Computer Applications. ACM and Saudi Arabia Sex Roles, 58(11/12), 752-760.

Ansari, Z.A. 2014. The relationship between religiosity and new product adoption. International Journal of Management Sciences, 2(6), 249-259.

Arnould, E., Price, L., Zinkhan, G. 2004. Consumers. McGraw-Hill. Irwin, New York.

Cleveland, M., Laroche, M., Hallab, R. 2013. Globalization, culture, religion, and values: Comparing consumption patterns of Lebanese Muslims and Christians. Journal of Business Research, 66(8), 958-967.

De Run, E.C., Butt, M.M., Fam, K.S., Jong, H.Y. 2010. Attitudes towards offensive advertising: Malaysian Muslims' views. Journal of Islamic Marketing.

Essoo, N., Dibb, S. 2010. Religious influences on shopping behaviour: an exploratory study. Journal of Marketing Management, 20(7-8), 683-712. http://doi.org/10.1362/0267257041838728.

Fam, K.S., Waller, D.S., Erdogan, B.Z. 2004. The influence of religion on attitudes towards the advertising of controversial products. European Journal of marketing. 
Gait, A., Worthington, A. 2008. An empirical survey of individual consumer, business firm and financial institution attitudes towards Islamic methods of finance. International Journal of Social Economics.

Gajjar, N.B. 2013. Factors affecting consumer behavior. International Journal of Research in Humanities and Social Sciences, 1(2), 10-15.

Johnson, B.R., Jang, S.J., Larson, D.B., De Li, S. 2001. Does adolescent religious commitment matter? A reexamination of the effects of religiosity on delinquency. Journal of Research in Crime and Delinquency, 38(1), 22-44.

Johnstone, R.L. 1975. Religion and society in interaction: The sociology of religion. Englewood Cliffs, NJ, Prentice-Hall.

Kalliny, M. 2010. Are they really that different from us: A comparison of Arab and American newspaper advertising. Journal of Current Issues \& Research in Advertising, 32(1), 95-108.

Khraim, H. 2010. Measuring Religiosity in Consumer Research from Islamic Perspective. International Journal of Marketing Studies, 2(2), 166-179. http://doi.org/10.5539/ijms.v2n2p166.

Luqmani, M., Yavas, U., Quraeshi, Z. 1989. Advertising in Saudi Arabia: content and regulation. International Marketing Review, 6(1).

Malik, S.I., Al-Emran, M. 2018. Social Factors Influence on Career Choices for Female Computer Science Students. International Journal of Emerging Technologies in Learning (IJET), 13(5), 56-70.

Mohamed, Z., Rezai, G., Shamsudin, M.N., Chiew, E.F.C. 2008. Halal logo and consumers' confidence: What are the important factors. Economic and Technology Management Review, 3(1), 37-45.

Mokhlis, S. 2008. Consumer religiosity and the importance of store attributes. The Journal of Human Resource and Adult Learning, 4(2), 122-133.

Mutsikiwa, M., Basera, C.H. 2012. The influence of socio-cultural variables on consumers' perception of halal food products: A case of masvingo urban, zimbabwe. International Journal of Business and Management, 7(20), 112.

Nassif, A., Gunter, B. 2008. Gender representation in television advertisements in Britainnewspaper advertising. Journal of Current Issues and Research in Advertising, 32(1).

Park, D.H., Lee, J. 2008. eWOM overload and its effect on consumer behavioral intention depending on consumer involvement. Electronic Commerce Research and Applications, 7(4), 386-398.

Rice, G., Al-Mossawi, M. 2002. The implications of Islam for advertising messages: The Middle Eastern context. Journal of Euromarketing, 11(3), 71-96.

Salloum, S.A.S., Shaalan, K. 2018. Investigating students' acceptance of E-learning system in Higher Educational Environments in the UAE: Applying the Extended Technology Acceptance Model (TAM). The British University in Dubai.

Salloum, S.A., Al-Emran, M., Shaalan, K., Tarhini, A. 2019. Factors affecting the E-learning acceptance: A case study from UAE. Education and Information Technologies, 24(1), 509-530.

Schiffman, L.G., Kanuk, L.L. 1997. The nature of consumer attitudes, Consumer Behavior.

Schiffman, L.G., Kanuk, L.L., Wisenblit, J. 2010. Consumer Behavior. Global Edition. Pearson Higher Education, London, 12(2), 113-120.

Stephen, A.T. 2016. The role of digital and social media marketing in consumer behavior. Current Opinion in Psychology, 10, 17-21. 
Taks, M., Shreim, M. 2009. The influence of Islam on shopping behaviour for sports apparel: An empirical study of Muslim immigrants. In Best practises in sport facility and event management: Conference proceedings, 326-328). Arko Sports Media/EASM; Nieuwegein ( $\mathrm{Nl})$.

Tuncalp, S. 1992. The audio-visual media in Saudi Arabia: problems and prospects. International Journal of Advertising, 11(2), 119-130. 